\title{
EVENTRATION OF LEFT HEMIDIAPHRAGM MIMICKING AS CAVITY
}

\section{A. P. Kansal' ${ }^{1}$ Daksh Jhim², Kiran Narayanappa ${ }^{3}$, Varinder Singh Bamrah ${ }^{4}$, Anand Kumar Bansal ${ }^{5}$}

1 Professor and HOD, Department of Chest and T.B, Government Medical College, Patiala. 2Junior Resident, Department of Chest and T.B, Government Medical College, Patiala. 3Junior Resident, Department of Chest and T.B, Government Medical College, Patiala. ${ }^{4} J$ unior Resident, Department of Chest and T.B, Government Medical College, Patiala. 5Junior Resident, Department of Chest and T.B, Government Medical College, Patiala.

ABSTRACT: Eventration of diaphragm is a condition in which there is abnormal elevation of the diaphragm as a result of thinning of muscular layer. It can be congenital as well as acquired. It is more common left sided. Herniation of the abdominal contents can be there. Clinical manifestations range from asymptomatic to life threatening respiratory distress requiring mechanical ventilator support. Ultrasound provides valuable information regarding the integrity of the diaphragm. Other imaging modalities include fluoroscopy, CT and MRI that provide valuable information when diagnosis is in doubt. We are presenting a case report of 25-yearold male with eventration of left hemidiaphragm mimicking as cavity. After taking detail history, examination and proper investigations we finally reached to this diagnosis.

KEYWORDS: Diaphragmatic Eventration, Hemidiaphragm, Diaphragmatic Paralysis, Diaphragmatic Hernia.

HOW TO CITE THIS ARTICLE: A. P. Kansal, Daksh Jhim, Kiran Narayanappa, Varinder Singh Bamrah, Anand Kumar Bansal. "Eventration of Left Hemidiaphragm Mimicking as Cavity". Journal of Evolution of Medical and Dental Sciences 2015; Vol. 4, Issue 88, November 02; Page: 15370-15372, DOI: 10.14260/jemds/2015/2188.

INTRODUCTION: Eventration of the diaphragm is an abnormal elevation of a thinned diaphragmatic muscle that causes elevation of the entire or part of the hemidiaphragm, or more commonly the anterior aspect of the hemidiaphragm. ${ }^{1}$ It is a rare anomaly with an incidence of 1 in 10,000 live births. $^{2}$ It is usually detected incidentally on chest X-ray or CT or when patient presents with chest complaints for other reasons. ${ }^{3}$ Clinical manifestations range from asymptomatic to life threatening respiratory distress requiring mechanical ventilator support. ${ }^{4} \mathrm{We}$ present a case report of a 25 -year-old male with left sided eventration of diaphragm mimicking a cavity.

CASE REPORT: A 25-year-old male presented to us with chief complaints of cough with expectoration and fever on and off since 3 months. Patient was on anti-tubercular therapy (ATT) since two and a half months on Chest X-ray basis. There was no improvement after taking ATT. General physical examination was normal. Chest examination revealed decreased movements on left side in inframammary, infra-axillary, and infrascapular areas.

Tactile vocal fremitus was decreased and note was tympanic on left inframammary, infra-axillary area. Breath sounds were decreased in the left inframammary, infraaxillary, and infrascapular areas. Sputum smear for AFB was negative. Laboratory investigations were normal. Chest Xray showed a cavity like picture in left lower zone but the left dome of diaphragm was not clear.

Financial or Other, Competing Interest: None.

Submission 09-10-2015, Peer Review 10-10-2015,

Acceptance 20-10-2015, Published 02-11-2015.

Corresponding Author:

Dr. Daksh Jhim,

Ho. No. 271, New Subhash Nagar, Maqsudan,

Jalandhar City-144008, Punjab, India.

E-mail: djdakshjhim@gmail.com

DOI:10.14260/jemds/2015/2188.
This raised our doubts. So CECT chest was ordered in this patient. The CECT chest showed raising of the left dome of the diaphragm with herniation of the abdominal contents into the thoracic cavity. Apart from this, there was a haemangioma in sixth segment of right lobe of liver. The mediastinal structures were well opacified with intravenous contrast and appeared normal in outline. There was no evidence of any mediastinal lymph node enlargement. Patient was managed symptomatically and was referred to Department of Surgery for further management.

With these clinical and radiological findings, a diagnosis of eventration of left diaphragm with herniation of abdominal contents into thoracic cavity was made.

DISCUSSION: Eventration of diaphragm is a rare condition in which there is thinning of the muscle fibres with only fibrous tissue left, leading to elevation of entire or part of the diaphragm. ${ }^{3,5}$ It is usually congenital but may also be acquired. ${ }^{6}$

It is more commonly left sided with characteristically marked mediastinal displacement to the right, a feature rarely seen with paralysis of the diaphragm. Muscle is thin and weak with movement reduced, paradoxical or absent on fluoroscopy. ${ }^{7}$ Ultrasound may present valuable information about integrity of the diaphragm with the content of eventration and other diaphragmatic pathologies. The other imaging modalities such as fluoroscopy, CT and MRI may be performed as adjunct techniques in cases where the diagnosis still remains in doubt, but they are unnecessary after ultrasound. ${ }^{8}$

The differential diagnosis includes diaphragmatic paralysis, diaphragmatic hernia, traction injury and iatrogenic injury after heart surgery. ${ }^{1}$ It can also occur in association with congenital syndromes like Kabuki make up syndrome, Beckwith-Wiedemann syndrome, Poland syndrome, Jarcho Levin syndrome, infections like fetal rubella, cytomegalovirus infection, trisomies, chromosomal abnormalities, and other congenital anomalies like pulmonary hypoplasia, congenital heart disease, tracheomalacia, cerebral agenesis, renal ectopia, 
malrotation, deformities of pinna, Meckel's diverticulum and Werdnig Hoffman disease. ${ }^{9,10}$

Asymptomatic patients are managed conservatively but patients with symptoms require surgery. Paradoxical movements suggest complete paralysis and if symptomatic, is a strong indication of surgery. ${ }^{5}$

In our case, eventration of left hemidiaphragm was diagnosed incidentally on clinical and radiological examination with herniation of abdominal contents into the thoracic cavity, when patient presented with chest infection. Patient was treated symptomatically and was referred to Department of Surgery for further management.

CONCLUSIONS: We want to stress on the point that a left sided eventration of diaphragm can mimic like a cavity as seen in our case. Clinicians should be careful while investigating such cases as wrong diagnosis can lead to pit fall. On the Chest X-ray basis, this case might be misdiagnosed as a cavity due to tuberculosis and unnecessarily putting patient on anti-tubercular therapy as seen in our case.

\section{REFERENCES:}

1. Robert MK, Bonita FS, Nina FS, Joseph WSG, Richard EB. Nelson textbook of Pediatrics. 19th edition, Saunders; Elsevier; 2012; 597.
2. Soni A, Singh P, Singh RJ, Sood V. Eventration of diaphragm-Embryological basis. J AnatSoc India. 2005; 54: 39-41.

3. Kulkarni ML, Sneharoopa B, Vani HN, Nawaz S, Kannan B, Kulkarni PM. Eventration of the diaphragm and associations. Indian J Pediatr; 74(2): 202-205.

4. Kiran B, Savitha B, Sunil Kumar R, Jai Maruthy DP, Prasanth G Patil. Eventration of Right Dome of Diaphragm Mimicking as Empyema. International Journal of Health Information and Medical Research Vol: 1, Issue: 4, Jul - Sep 2014.

5. Kansal AP, Chopra V, Chahal AS, Grover CS, Singh H, and Kansal S.Right-sided diaphragmatic eventration: A rare entity. Lung India. 2009 Apr-Jun; 26(2): 48-50.

6. Laxdale $\mathrm{OE}$, McDougall $\mathrm{H}$, Mellin GW. Congenital eventration of the diaphragm. N Engl Med.1954; 250:401.

7. David Sutton, ed. Text Book of Radiology and Imaging, 7th edition, Churchill Livingstone. London 2003; 51-52.

8. Eren S, Ceviz N, Alper F. Congenital diaphragmatic eventration as a cause of anterior mediastinal mass in the children: imaging modalities and literature review. Eur J Radiol 2004 Jul; 51(1): 85-90.

9. Jones KL, ed. Smith's recognisable patterns of human malformation, 5th edition, Philadelphia; WB Saunders, 1997; 116-302.

10. Irene MI, Booker PD. Congenital diaphragmatic hernia and eventration of diaphragm. In Lister J, Irene MI, eds. Neonatal surgery, $3^{\text {rd }}$ edition; Butterworth, 1990; 214.

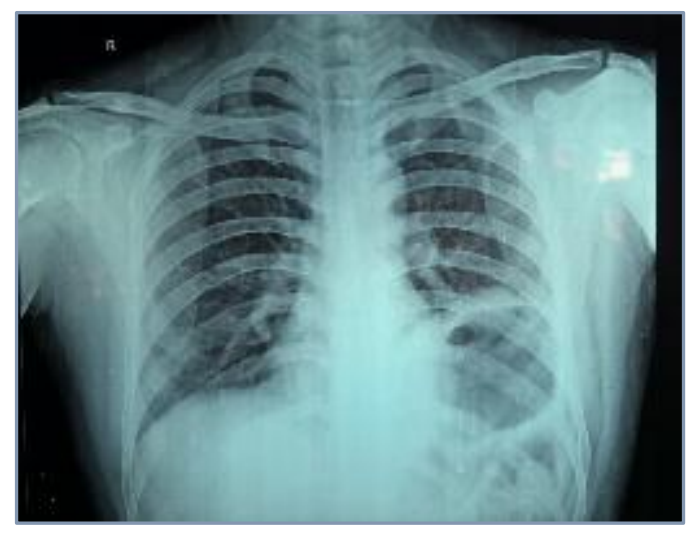

Fig. 1: Chest X-ray showing a cavity like picture in left lower zone

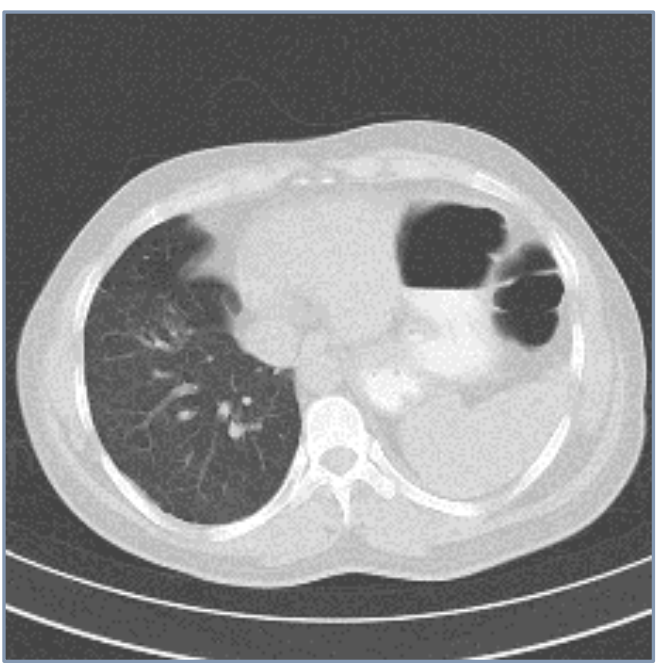

Fig. 2: CECT Chest showing eventration of left hemidiaphragm with herniation of abdominal contents 


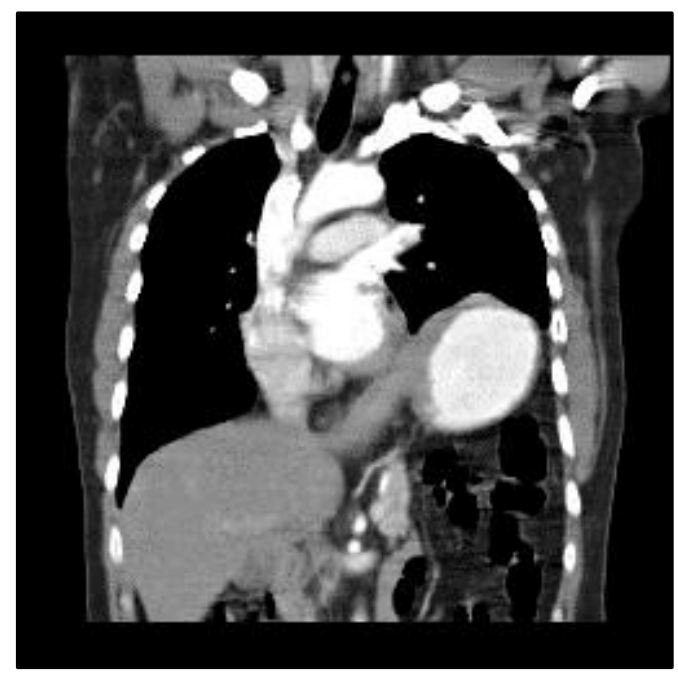

Fig. 3: CECT Chest showing herniation of abdominal contents into left hemithorax 